University of Wollongong

Research Online

Australian Institute for Innovative Materials -

Papers

Australian Institute for Innovative Materials

$1-1-2014$

\title{
Large scale production of novel g-C3N4 micro strings with high surface area and versatile photodegradation ability
}

Muhammad Nawaz Tahir

Beijing Institute of Technology

Chuanbao Cao

Beijing Institute of Technology

Faheem K. Butt

Beijing Institution of Technology

Sajid Butt

Tsinghua University

Faryal Idrees

Beijing Institution Of Technology

See next page for additional authors

Follow this and additional works at: https://ro.uow.edu.au/aiimpapers

Part of the Engineering Commons, and the Physical Sciences and Mathematics Commons

Research Online is the open access institutional repository for the University of Wollongong. For further information contact the UOW Library: research-pubs@uow.edu.au 


\title{
Large scale production of novel g-C3N4 micro strings with high surface area and versatile photodegradation ability
}

\begin{abstract}
An easy, scalable and environmentally benign chemical method has been developed to synthesize micro strings of graphitic-C3N4 (msg-C3N4) through pre-treatment of melamine with HNO 3 in alkaline solvent at low temperature. This methodology results in a unique string type morphology of msg-C3N4 with higher surface area. These msg-C3N4 micro strings were used as a photocatalyst under visible light for photodegradation of rhodamine $\mathrm{B}$, methyl blue and methyl orange. The msg-C3N4 shows enhanced photodegradation efficiency due to its high surface area and favourable bandgap. The first order rate constant for msg-C3N4 was measured which confirms the higher performance of msg-C3N4 in comparison to other reported materials such as g-C3N4, Fe2O3/g-C3N4 and TiO2 nanotubes. Thus, the method developed here is favourable for the synthesis of materials with higher surface area and unique morphology, which are favourable for high photodegradation activity. The Royal Society of Chemistry.
\end{abstract}

\section{Keywords}

scale, large, c, inf, 3, production, novel, g, n, 4, ability, micro, strings, photodegradation, versatile, area, surface, high

Disciplines

Engineering | Physical Sciences and Mathematics

\section{Publication Details}

Tahir, M., Cao, C., Butt, F. K., Butt, S., Idrees, F., Ali, Z., Aslam, I., Tanveer, M., Mahmood, A. \& Mahmood, N. (2014). Large scale production of novel g-C3N4 micro strings with high surface area and versatile photodegradation ability. CrystEngComm, 16 (9), 1825-1830.

\section{Authors}

Muhammad Nawaz Tahir, Chuanbao Cao, Faheem K. Butt, Sajid Butt, Faryal Idrees, Zulfiqar Ali, Imran Aslam, M Tanveer, Asif Mahmood, and Nasir Mahmood 


\section{CrystEngComm}

Cite this: CrystEngComm, 2014, 16 1825

Received 22nd October 2013,

Accepted 26th November 2013

DOI: $10.1039 / c 3 c e 42135 j$

www.rsc.org/crystengcomm

\section{Large scale production of novel g- $\mathrm{C}_{3} \mathrm{~N}_{4}$ micro strings with high surface area and versatile photodegradation ability $\dagger$}

\author{
Muhammad Tahir, ${ }^{a}$ Chuanbao Cao, ${ }^{\text {a }}$ Faheem K. Butt, ${ }^{a}$ Sajid Butt, ${ }^{\text {b }}$ Faryal Idrees, ${ }^{a}$ \\ Zulfiqar Ali, ${ }^{a}$ Imran Aslam, ${ }^{a}$ M. Tanveer, ${ }^{a}$ Asif Mahmood $^{\mathrm{C}}$ and Nasir Mahmood ${ }^{\mathrm{C}}$
}

\begin{abstract}
An easy, scalable and environmentally benign chemical method has been developed to synthesize micro strings of graphitic- $\mathrm{C}_{3} \mathrm{~N}_{4}$ (msg- $\left.\mathrm{C}_{3} \mathrm{~N}_{4}\right)$ through pre-treatment of melamine with $\mathrm{HNO}_{3}$ in alkaline solvent at low temperature. This methodology results in a unique string type morphology of $m s g-C_{3} N_{4}$ with higher surface area. These msg- $\mathrm{C}_{3} \mathrm{~N}_{4}$ micro strings were used as a photocatalyst under visible light for photodegradation of rhodamine $\mathrm{B}$, methyl blue and methyl orange. The msg- $\mathrm{C}_{3} \mathrm{~N}_{4}$ shows enhanced photodegradation efficiency due to its high surface area and favourable bandgap. The first order rate constant for msg- $\mathrm{C}_{3} \mathrm{~N}_{4}$ was measured which confirms the higher performance of $\mathrm{msg}-\mathrm{C}_{3} \mathrm{~N}_{4}$ in comparison to other reported materials such as $\mathrm{g}-\mathrm{C}_{3} \mathrm{~N}_{4}, \mathrm{Fe}_{2} \mathrm{O}_{3} / \mathrm{g}-\mathrm{C}_{3} \mathrm{~N}_{4}$ and $\mathrm{TiO}_{2}$ nanotubes. Thus, the method developed here is favourable for the synthesis of materials with higher surface area and unique morphology, which are favourable for high photodegradation activity.
\end{abstract}

\section{Introduction}

Environmental problems have been increasing at exponential rates in recent years due to global warming. A lot of research has been devoted to solve these concerns. One of the approaches to solve these issues is to make use of sunlight for decomposing harmful chemicals present in the environment. Harvesting solar energy is very important in the context of solving environmental issues as the source is always emitting energy at a high rate and energy is available around the globe. This energy can be efficiently utilized using species that can convert solar energy into applicable form.

The search for optimized and highly efficient photocatalysts is highly needed to deal with environmental concerns. Photocatalysis is used to remove pollutants through photooxidation in the presence of light and photocatalyst. ${ }^{1,2}$ These nano-robots or nano-sweepers require strong oxidative ability, a suitable bandgap and excellent stability in water solution.

\footnotetext{
${ }^{a}$ Research Center of Materials Science, Beijing Institute of Technology, Beijing 100081, People's Republic of China. E-mail: cbcao@bit.edu.cn; Fax: +86 106891 2001; Tel: +861068913792

${ }^{b}$ School of Materials Science and Engineering Tsinghua University, Beijing 100081, People's Republic of China

${ }^{c}$ Department of Materials Science and Engineering, Peking University, Beijing 100081, PR China

$\dagger$ Electronic supplementary information (ESI) available: SEM and XRD of growth mechanism, digital photograph of $\mathrm{msg}^{-} \mathrm{C}_{3} \mathrm{~N}_{4}, C / C_{0}$ of $\mathrm{RhB}, k$ value of $\mathrm{RhB}$ with different concentration and efficiency of $m s g-\mathrm{C}_{3} \mathrm{~N}_{4}$ can be found in ESI. See DOI: 10.1039/c3ce42135j
}

Various semiconductors have been proposed as photocatalysts during recent decades, such as metal oxides, sulphides and oxy-nitrides. ${ }^{3,4}$ Among them, numerous metal (Ag, Au, Pt and $\mathrm{Pd}$ ) nanostructures have shown good photocatalytic response due to their large surface area but have some issues due to agglomeration and stability over a period of time. ${ }^{5}$ Consequently, new photocatalysts that are stable, efficient, inexpensive, non-toxic and capable of harvesting sunlight are highly desirable.

Graphitic carbon nitride $\left(\mathrm{g}-\mathrm{C}_{3} \mathrm{~N}_{4}\right)$ is a promising material with excellent mechanical and thermal properties, a catalyst for organic synthesis, a photoelectric converter, an electrode material for fuel cells or batteries, a hydrogen storage material and a fluorescent sensor. ${ }^{6-8}$ g- $\mathrm{C}_{3} \mathrm{~N}_{4}$, a metal free catalyst, has been investigated as an environmentally friendly photocatalyst for photodegradation of organic pollutants in water. ${ }^{8,9}$ Fast recombination of photogenerated charge carriers and the low surface area of $\mathrm{g}-\mathrm{C}_{3} \mathrm{~N}_{4}$ limits the search for high efficiency. Thus, various attempts have been made to solve these problems, e.g. doping with heteroatoms, tuning compositions, coupling with other semiconductors and preparation of nano or porous $\mathrm{g}-\mathrm{C}_{3} \mathrm{~N}_{4} \cdot{ }^{9-20}$

The morphology, size, shape, dimension and surface area of nanostructures are key features for photocatalytic activities. ${ }^{21-26}$ Unfortunately the surface areas of $\mathrm{g}-\mathrm{C}_{3} \mathrm{~N}_{4}$ fabricated from precursors such as melamine, cyanamide and dicyanamide are very small $\left(\sim 15 \mathrm{~m}^{2} \mathrm{~g}^{-1}\right) \cdot{ }^{27}$ In order to achieve high surface area several template methods have been investigated, for example $\mathrm{Xu}$ et al. fabricated $\mathrm{g}-\mathrm{C}_{3} \mathrm{~N}_{4}$ with a surface 
area of $128 \mathrm{~m}^{2} \mathrm{~g}^{-1}$, Wang et al. synthesized $\mathrm{g}-\mathrm{C}_{3} \mathrm{~N}_{4}$ with a high surface area of $239 \mathrm{~m}^{2} \mathrm{~g}^{-1}$ and Yuliati et al. also synthesized g- $\mathrm{C}_{3} \mathrm{~N}_{4}$ with a surface area of $224 \mathrm{~m}^{2} \mathrm{~g}^{-1} \cdot{ }^{27-34}$ The resultant g- $\mathrm{C}_{3} \mathrm{~N}_{4}$ showed superior photocatalytic activities toward photodegradation or hydrogen production but their practical application was limited since the template was removed by $\mathrm{HF}$, which poisoned the product. Elimination of the template removal process could increase practical application of the material. Designing a specific morphology also gives enhanced properties to the product e.g. string-like structures have advantages of large aspect ratio, low density, good chemical and environmental stability. Moreover, the string-like morphology also had advantages over nanowires and nanotubes in lithiation and de-lithiation processes in lithium ion batteries. ${ }^{33}$ Thus, an easy and scalable method is required to prepare g- $\mathrm{C}_{3} \mathrm{~N}_{4}$ with high surface area and specific morphology without using templates and toxic chemicals to make its application more practical in the fields of catalysis and energy storage.

Here, we report a large scale, controlled synthesis of g- $\mathrm{C}_{3} \mathrm{~N}_{4}$ micro strings by pre-treatment of melamine with $\mathrm{HNO}_{3}$. To the best of our knowledge these strings have not been reported yet and the methodology developed is easy, economical, works at low temperature and is template free. In order to study the possible growth mechanism of $\mathrm{msg}^{-} \mathrm{C}_{3} \mathrm{~N}_{4}$, time-dependent experiments were performed and appropriate conditions were defined. Moreover, the effects of the solvent and $\mathrm{HNO}_{3}$ on the morphology of $\mathrm{msg}^{-} \mathrm{C}_{3} \mathrm{~N}_{4}$ were also explored. The $\mathrm{msg}^{-} \mathrm{C}_{3} \mathrm{~N}_{4}$ was used as a photocatalyst for rhodamine $\mathrm{B}$ (RhB), methyl blue (MB) and methyl orange (MO) degradation under visible light. Results suggest improved photocatalytic performance without considerable loss of efficiency upon recycling. Therefore, by using current methodology, higher surface area and novel morphology can be achieved simultaneously, which are favorable for high photocatalytic activity.

\section{Experimental section}

\section{Preparation of $\mathrm{msg}_{-}-\mathrm{C}_{3} \mathrm{~N}_{4}$}

$1 \mathrm{~g}$ melamine was dissolved in $20 \mathrm{ml}$ of ethylene glycol with continuous stirring, followed by addition of $60 \mathrm{ml}$ of $0.2 \mathrm{M}$ $\mathrm{HNO}_{3}$ solution. The resultant mixture was stirred for 10 minutes. Finally, the product was washed with ethanol and dried at $80{ }^{\circ} \mathrm{C}$. After drying, the obtained white powder was annealed at $400{ }^{\circ} \mathrm{C}$ for $2 \mathrm{~h}$ in a muffle furnace in alumina crucibles. After annealing, a yellowish powder was collected and stored for characterization. In addition, bulk $\mathrm{g}-\mathrm{C}_{3} \mathrm{~N}_{4}$ was also prepared according to the literature. ${ }^{9}$ Sample was characterized by scanning electron microscopy (SEM), transmission electron microscopy (TEM), selected-area electron diffraction (SAED), X-ray diffraction (XRD), X-ray photoelectron spectroscopy (XPS) and photoluminescence absorption spectroscopy (PL).

\section{Photocatalytic test}

For photocatalytic tests, a certain amount of sample was dissolved in $40 \mathrm{ml}$ aqueous solutions of $\mathrm{RhB}, \mathrm{MB}$ or $\mathrm{MO}$ in glass beakers. The concentration of $\mathrm{RhB}, \mathrm{MB}$ and $\mathrm{MO}$ was $10 \mathrm{mg}$ in $1 \mathrm{~L}$ of $\mathrm{H}_{2} \mathrm{O}$. At first, the solution was stirred continuously in the dark for 30 minutes to establish adsorptiondesorption equilibrium among the photocatalysts and dye solution, then this solution was brought into visible light. A $500 \mathrm{~W}$ xenon lamp was used as a visible light source and the glass beaker was placed in front of the lamp during continuous magnetic stirring. $3 \mathrm{ml}$ of solution was taken and UV absorption measurements were used to observe the photodegradation at specific time intervals. Every time before measuring UV, the solution was centrifuged to remove the suspension particles of the catalyst. The absorption peaks for $\mathrm{RhB}, \mathrm{MB}$ and MO were observed at 554, 610 and $465 \mathrm{~nm}$ respectively. For stability measurements the same materials were taken from the solution and the above mentioned steps were repeated for second and third times.

\section{Results and discussion}

Characterization of the $\mathrm{msg}^{-} \mathrm{C}_{3} \mathrm{~N}_{4}$

X-ray diffraction (XRD) study was performed in order to investigate the crystal structure and phase of the as-prepared samples. Two distinctive XRD peaks were observed for $\mathrm{g}-\mathrm{C}_{3} \mathrm{~N}_{4}$ at $27.5^{\circ}$ and $13.1^{\circ}$ as shown in Fig. 1(a). The strong peak at $27.5^{\circ}$ corresponds to the long-range inter-planar stacking of aromatic systems with an inter-planar distance of $0.324 \mathrm{~nm}$. The small peak at $13.1^{\circ}(100)$ is related to $d=0.76 \mathrm{~nm}$ because of in-plane structural packing motif. However, there is only one broad peak at $27.3^{\circ}$ for $\mathrm{msg}^{-} \mathrm{C}_{3} \mathrm{~N}_{4}$ resembling that at $27.5^{\circ}$ for $\mathrm{g}-\mathrm{C}_{3} \mathrm{~N}_{4}$ related to (002), showing that the msg- $\mathrm{C}_{3} \mathrm{~N}_{4}$ peak is slightly shifted and its corresponding
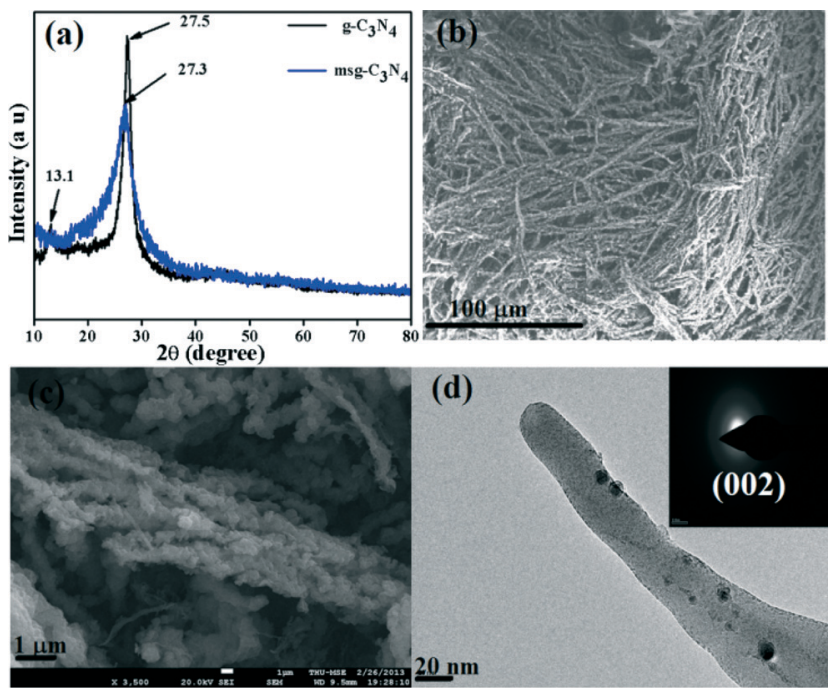

Fig. 1 (a) XRD patterns of msg- $\mathrm{C}_{3} \mathrm{~N}_{4}$ and g- $\mathrm{C}_{3} \mathrm{~N}_{4}$; (b) low and (c) high magnification SEM images of $\mathrm{msg}-\mathrm{C}_{3} \mathrm{~N}_{4}$; (d) TEM image and SAED pattern (inset) of msg- $\mathrm{C}_{3} \mathrm{~N}_{4}$. 
inter-planer distance $0.326 \mathrm{~nm}$ is increased as compared to $\mathrm{g}-\mathrm{C}_{3} \mathrm{~N}_{4} \cdot{ }^{35-37}$

The morphology and microstructures of $\mathrm{msg}^{-} \mathrm{C}_{3} \mathrm{~N}_{4}$ were characterized through SEM and TEM as shown in Fig. 1(b-d). From Fig. 1(b), it is obvious that as-prepared micro strings are uniform and dense without aggregation. These $m s g-C_{3} N_{4}$ have an aspect ratio of 50, as their length is in the range of tens of microns and their diameter is $2-4$ micrometers. From Fig. 1(b), it is obvious that as-synthesized $m s g-\mathrm{C}_{3} \mathrm{~N}_{4}$ has a well-defined string structure with large accommodation sites for host species as shown in Fig. 1(c). Furthermore, the TEM image delineated in Fig. 1(d) confirmed growth of the strings with uniform dimensions. SAED studies were carried out (inset of Fig. 1d) to further confirm the structure of msg- $\mathrm{C}_{3} \mathrm{~N}_{4}$. Thus, the diffraction ring indexed as (002) is in accordance with the XRD result (Fig. 1(d)) with $d=0.33 \mathrm{~nm}$.

In order to probe the chemical compositions and chemical states of the $\mathrm{msg}^{-} \mathrm{C}_{3} \mathrm{~N}_{4}$, XPS characterization was performed as shown in Fig. 2. The C1s spectrum has two peaks at $288.15 \mathrm{eV}$ and $284.6 \mathrm{eV}$, which are attributed to the existence of $\mathrm{C}-\mathrm{N}-\mathrm{C}$ coordination and surface adventitious carbon, respectively, as shown in Fig. 2(a). ${ }^{37}$ Similarly, the N1s spectra

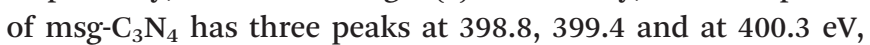
which correspond to pyridinic, amino and pyrrolic nitrogen centres, respectively. The $\mathrm{C} / \mathrm{N}$ ratio of $\mathrm{msg}-\mathrm{C}_{3} \mathrm{~N}_{4}$ calculated using XPS is 0.82, a little higher in comparison with the theoretical value of 0.75 , which proves that $m s g-\mathrm{C}_{3} \mathrm{~N}_{4}$ has a low concentration of $\mathrm{N}$. In order to study the growth mechanism of msg- $\mathrm{C}_{3} \mathrm{~N}_{4}$, time-dependent experiments were performed and appropriate conditions were optimized. In this context, melamine was treated with $\mathrm{HNO}_{3}$ and the mixture was calcined. For growth studies, products were collected and studied at different time intervals (60, 90, 120, 150 minutes) during the calcination process. It is obvious that melamine particles (Fig. 3(a)) were converted into rod type structures (Fig. 3(b)) as a result of calcination for first 60 minutes. Product collected after 90 minutes suggests the destruction of rods and formation of small beads (Fig. 3(c)). Prolonged calcination up to 120 minutes leads to fusion of these beads and formation of small string type structures (Fig. 3(d)). Further increase in exposure time up to 150 minutes at the same temperature leads to fusion of stray strings together and formation of long micro strings with high aspect ratio, as shown in Fig. 3(d-e). The presence of
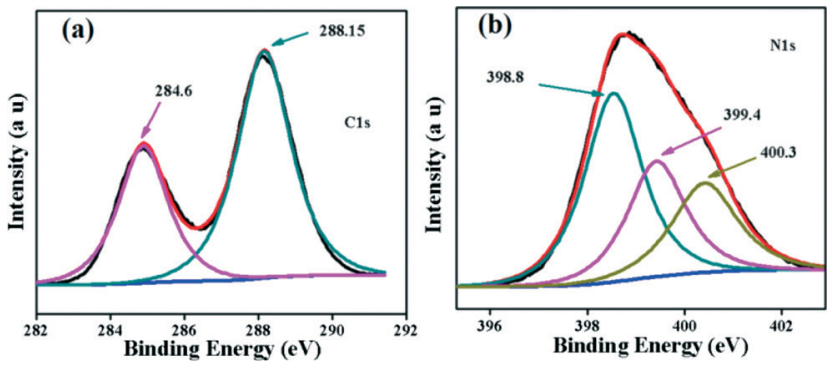

Fig. 2 XPS spectra of $\mathrm{msg}^{-} \mathrm{C}_{3} \mathrm{~N}_{4}$ : (a) C1s, (b) N1s.

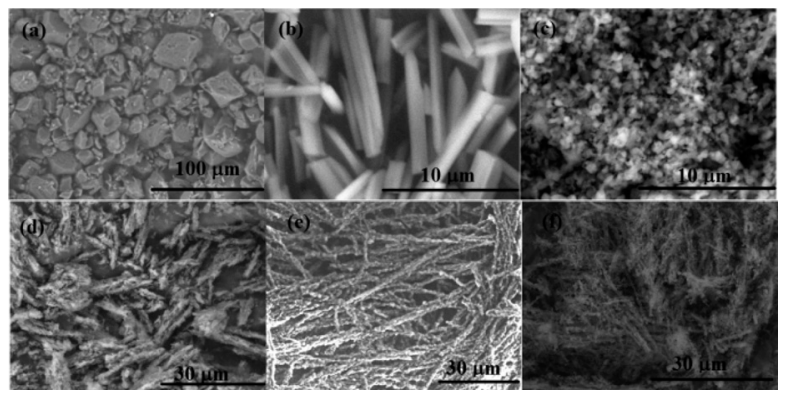

Fig. 3 SEM images of (a) melamine, (b) nanorods, (c) $m s g-C_{3} \mathrm{~N}_{4}$ after 60 minutes, (d) $m s g-C_{3} N_{4}$ after 90 minutes, (e) $m s g-C_{3} N_{4}$ after 120 minutes, (f) $\mathrm{msg}-\mathrm{C}_{3} \mathrm{~N}_{4}$ after 150 minutes.

small beads on the surface of these strings is also obvious, which suggests further growth of these micro strings in the case of the presence of more reactive species. SEM images of the intermediate and final products without $\mathrm{HNO}_{3}$ and ethylene glycol are also given in Fig. S3†.

XRD patterns of melamine and $\mathrm{msg}^{-} \mathrm{C}_{3} \mathrm{~N}_{4}$ heated at different time periods are presented in Fig. $\mathrm{S} 4 \uparrow$. The XRD patterns of rods and melamine are different from each other, which confirms the advantages of pre-treatment of melamine with $\mathrm{HNO}_{3}$, which converts melamine to nanoparticles as shown in Fig. S3. $\dagger$ The other samples are identified as $\mathrm{g}$-(002) with peak positions $26.5^{\circ}, 26.9^{\circ}, 27.3^{\circ}$ and $27.5^{\circ}$ after $60,90,120$ and 150 minutes, respectively. The intensity of the peak also increases with time, which indicates enhancement in the quality and stability of the crystal structure, but a longer time period (150 minutes) destroy the string morphology. Furthermore, the inter-planar distance $d$ for all the samples is less than $0.326 \mathrm{~nm}$.

FTIR spectra of melamine, intermediate product (rods), msg- $\mathrm{C}_{3} \mathrm{~N}_{4}$ and $\mathrm{g}-\mathrm{C}_{3} \mathrm{~N}_{4}$ are shown in Fig. $\mathrm{S} 5 \dagger$. The peaks in the range of $3300-3500 \mathrm{~cm}^{-1}$ are assigned to the stretching vibration modes of $\mathrm{NH}$ and $\mathrm{NH}_{2}$ groups and are observed in all the samples. ${ }^{38,39}$ The absorption peaks from $800 \mathrm{~cm}^{-1}$ to $1400 \mathrm{~cm}^{-1}$ related to the breathing mode of $s$-triazine, amorphous $\mathrm{sp}^{3} \mathrm{C}-\mathrm{C}$ bonds and $\mathrm{C}-\mathrm{N}$ are also examined in all the samples; these results are consistent with the XRD and XPS results of $\mathrm{msg}^{-\mathrm{C}_{3}} \mathrm{~N}_{4} \cdot{ }^{15,30}$ The peak at $1697 \mathrm{~cm}^{-1}$ is only present in the nanorods because of the existence of $\mathrm{C}=\mathrm{O}$ bonds. ${ }^{40}$ The presence of $\mathrm{C}=\mathrm{O}$ plays a critical role in the formation of $\mathrm{msg}^{-} \mathrm{C}_{3} \mathrm{~N}_{4}$. This $\mathrm{C}=\mathrm{O}$ is only formed when melamine is pre-treated with $\mathrm{HNO}_{3}$ in the presence of ethylene glycol. In the absence of $\mathrm{HNO}_{3}$ or ethylene glycol this $\mathrm{C}=\mathrm{O}$ is not formed, due to which the $\mathrm{msg}^{-} \mathrm{C}_{3} \mathrm{~N}_{4}$ is also not achieved as discussed above.

PL studies were carried out at room temperature to study the bandgap of the synthesized materials $\left(\mathrm{g}-\mathrm{C}_{3} \mathrm{~N}_{4}\right.$ and msg- $\mathrm{C}_{3} \mathrm{~N}_{4}$ ) as shown in Fig. 4(a). UV light of $325 \mathrm{~nm}$ wavelength was used to excite the materials. The broad peak of $\mathrm{msg}^{-} \mathrm{C}_{3} \mathrm{~N}_{4}$ and $\mathrm{g}-\mathrm{C}_{3} \mathrm{~N}_{4}$ at 427.6 and $452 \mathrm{~nm}$, respectively, correspond to the bandgap of the respective samples. The bandgap of msg- $_{3} \mathrm{~N}_{4}$ was calculated to be $2.9 \mathrm{eV}$ as compared to $2.72 \mathrm{eV}$ of $\mathrm{g}-\mathrm{C}_{3} \mathrm{~N}_{4}$. This is due to perfect packing and 

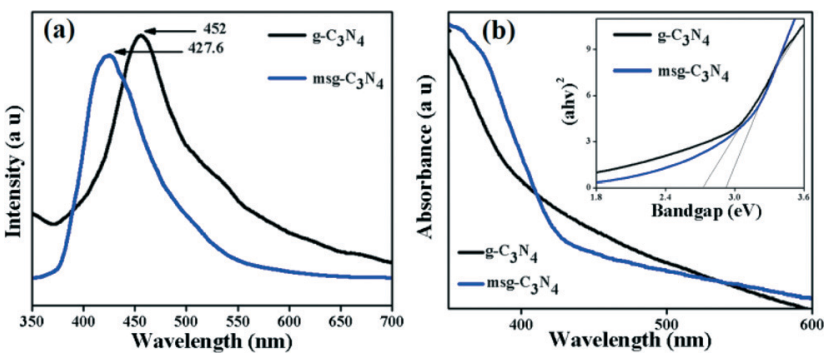

Fig. 4 (a) PL spectra of msg- $C_{3} N_{4}$ and $g-C_{3} N_{4}$; (b) UV spectrum of msg- $\mathrm{C}_{3} \mathrm{~N}_{4}$ and g- $\mathrm{C}_{3} \mathrm{~N}_{4}$ along with their bandgap (inset).

electronic coupling between the layers of single and nonconnected msg- $\mathrm{C}_{3} \mathrm{~N}_{4}$ and quantum confinement effects that shift conduction and valence band edges in opposite directions. ${ }^{40,41}$ Therefore, it is believed that the bandgap with high energy level would acquire thermodynamically improved reduction and oxidation power in photodegradation of dyes. The charge-transfer rate between $\mathrm{msg}^{-} \mathrm{C}_{3} \mathrm{~N}_{4}$ and redox species in solution also depends on these energy level relation. ${ }^{40}$ Also, the PL intensity of msg- $\mathrm{C}_{3} \mathrm{~N}_{4}$ is strong in comparison to g- $\mathrm{C}_{3} \mathrm{~N}_{4}$, which indicates that the msg- $\mathrm{C}_{3} \mathrm{~N}_{4}$ can be used as light-emitting material with high fluorescence quantum yield. $^{42,43}$ In order to further confirm the bandgap, UV studies were carried out. The UV spectra of msg- $\mathrm{C}_{3} \mathrm{~N}_{4}$ and g- $\mathrm{C}_{3} \mathrm{~N}_{4}$ along with their corresponding bandgaps are shown in Fig. 4(b). The bandgap of $\mathrm{msg}^{-} \mathrm{C}_{3} \mathrm{~N}_{4}$ is $2.9 \mathrm{eV}$ and the bandgap of $\mathrm{g}-\mathrm{C}_{3} \mathrm{~N}_{4}$ is $2.72 \mathrm{eV}$, in good agreement with the PL studies.

The surface area of the samples was calculated with the Brunauer-Emmett-Teller (BET) method in the relative pressure range of $0-1$ by using $3 \mathrm{H}-2000 \mathrm{PS} 2$, China. The $\mathrm{msg}^{-} \mathrm{C}_{3} \mathrm{~N}_{4}$ has a large surface area of $290 \mathrm{~m}^{2} \mathrm{~g}^{-1}$ as compared to $10 \mathrm{~m}^{2} \mathrm{~g}^{-1}$ for $\mathrm{g}^{-} \mathrm{C}_{3} \mathrm{~N}_{4}$. The surface area of $\mathrm{msg}^{-} \mathrm{C}_{3} \mathrm{~N}_{4}$ is 29 times greater than that of $\mathrm{g}-\mathrm{C}_{3} \mathrm{~N}_{4}$, which can also be observed from Fig. S7 $\uparrow$. Thus, because of its large surface area msg- $\mathrm{C}_{3} \mathrm{~N}_{4}$ provides more photocatalytic reaction sites for the adsorption of reactant molecules and increases the efficiency of the electron-hole separation, so the photocatalytic activity of msg- $\mathrm{C}_{3} \mathrm{~N}_{4}$ is enhanced. Moreover, this large surface area also makes $\mathrm{msg}^{-} \mathrm{C}_{3} \mathrm{~N}_{4}$ a promising candidate for hydrogen production. ${ }^{8}$

\section{Photocatalytic performance of $\mathbf{m s g}-\mathrm{C}_{3} \mathrm{~N}_{4}$}

The photocatalytic activity of the $\mathrm{msg}^{-} \mathrm{C}_{3} \mathrm{~N}_{4}$ was evaluated by degradation of $\mathrm{RhB}$, MO and $\mathrm{MB}$ under visible light (wavelength $>420 \mathrm{~nm}$ ) irradiation in order to demonstrate its potential application for wastewater treatment. For the degradation of RhB, different amounts $(10 \mathrm{mg}, 20 \mathrm{mg}, 50 \mathrm{mg}$ and $100 \mathrm{mg}$ ) of $\mathrm{msg}_{-} \mathrm{C}_{3} \mathrm{~N}_{4}$ and $\mathrm{g}-\mathrm{C}_{3} \mathrm{~N}_{4}$ were taken to explore the effect of concentration of photocatalysts upon $\mathrm{RhB}$ degradation. Fig. S12† shows the relationship between $C / C_{0}$ and time $\left(C_{0}\right.$ is the initial concentration of the RhB, $C$ is the concentration at time $t$ ) of all samples and for comparison a primary solution was irradiated without catalyst under visible light. The sample without catalyst does not show any appreciable changes with time. ${ }^{7,9}$

Fig. 5(a) shows the relationship between $C / C_{0}$ and time for $\mathrm{RhB}, \mathrm{MB}$ and $\mathrm{MO}$ with $100 \mathrm{mg}$ concentration of msg- $\mathrm{C}_{3} \mathrm{~N}_{4}$ and g- $\mathrm{C}_{3} \mathrm{~N}_{4}$. The msg- $\mathrm{C}_{3} \mathrm{~N}_{4}$ took just 45 minutes to completely degrade $\mathrm{RhB}$ whereas $\mathrm{g}-\mathrm{C}_{3} \mathrm{~N}_{4}$ required 75 minutes for complete degradation of $\mathrm{RhB}$ and a linear decrease in $C / C_{0}$ with time was observed. Similarly, the $\mathrm{msg}^{-} \mathrm{C}_{3} \mathrm{~N}_{4}$ needed only 60 minutes for complete degradation of $\mathrm{MB}$ whereas $\mathrm{g}_{-} \mathrm{C}_{3} \mathrm{~N}_{4}$ required 120 minutes for the same. Also for $\mathrm{MO}, \mathrm{msg}-\mathrm{C}_{3} \mathrm{~N}_{4}$ took 165 minutes as compared to $\mathrm{g}-\mathrm{C}_{3} \mathrm{~N}_{4}$ which needed 270 minutes for complete degradation of the dye (Fig. S8-S13 $\uparrow$ ). Fig. 5(b) shows the first order rate constant $k\left(\mathrm{~min}^{-1}\right)$ of $\mathrm{msg}^{-} \mathrm{C}_{3} \mathrm{~N}_{4}$ and $\mathrm{g}_{-} \mathrm{C}_{3} \mathrm{~N}_{4}$ for $\mathrm{RhB}, \mathrm{MB}$ and MO, which was calculated by the following first order equation:

$$
\ln \left(C_{0} / C=k t\right)
$$

where $C_{0}$ is the initial concentration of the dye in solution and $C$ is the concentration of dye at time $t . k$ has maximum value of $0.0372 \mathrm{~min}^{-1}$ for $\mathrm{RhB}$ when $\mathrm{msg}^{-\mathrm{C}_{3} \mathrm{~N}_{4}}$ is used as a catalyst and it decreased to $0.0217 \mathrm{~min}^{-1}$ in the case of $\mathrm{g}_{-} \mathrm{C}_{3} \mathrm{~N}_{4}$. Furthermore, it is $0.03336 \mathrm{~min}^{-1}$ for msg- $\mathrm{C}_{3} \mathrm{~N}_{4}$ of $\mathrm{MB}$ and $0.0185 \mathrm{~min}^{-1}$ for $\mathrm{g}-\mathrm{C}_{3} \mathrm{~N}_{4}$. It also showed the improved performance for MO in the case of msg- $\mathrm{C}_{3} \mathrm{~N}_{4}$ as compared to $\mathrm{g}-\mathrm{C}_{3} \mathrm{~N}_{4}$. In Table $\mathrm{S} 1, \uparrow k$ values of carbon nitride and $\mathrm{TiO}_{2}$ are given for comparison, which confirms that the msg- $\mathrm{C}_{3} \mathrm{~N}_{4}$ is a more effective photocatalyst. Fig. S14 $\uparrow$ shows $k\left(\mathrm{~min}^{-1}\right)$ of $\mathrm{msg}_{-}-\mathrm{C}_{3} \mathrm{~N}_{4}$ and $\mathrm{g}-\mathrm{C}_{3} \mathrm{~N}_{4}$ for $\mathrm{RhB}$ with different amount of samples. The $\mathrm{msg}^{-} \mathrm{C}_{3} \mathrm{~N}_{4}$ with mass $50 \mathrm{mg}$ has maximum $k=0.06603 \mathrm{~min}^{-1}$, which was almost double that of $\mathrm{g}^{-} \mathrm{C}_{3} \mathrm{~N}_{4}$. The formation of $\mathrm{C}=\mathrm{O}$ bonds in the intermediate state leads to the novel structure of $\mathrm{msg}^{-} \mathrm{C}_{3} \mathrm{~N}_{4}$, which is highly useful for a higher value of $k\left(\mathrm{~min}^{-1}\right)$. The presence of small beads on the surface of micro strings, which extend their network deep into the strings (as suggested by SEM and BET), act as the reaction sites for the photocatalytic activity. Also, the small particle size of $\mathrm{g}^{-} \mathrm{C}_{3} \mathrm{~N}_{4}$ tends to agglomerate into large particles, resulting in a poor photocatalytic performance of $\mathrm{g}-\mathrm{C}_{3} \mathrm{~N}_{4}$ as compared to $\mathrm{msg}_{-} \mathrm{C}_{3} \mathrm{~N}_{4}$.

The stability and reproducibility of the photocatalysts is highly important for its practical applications. In this context,

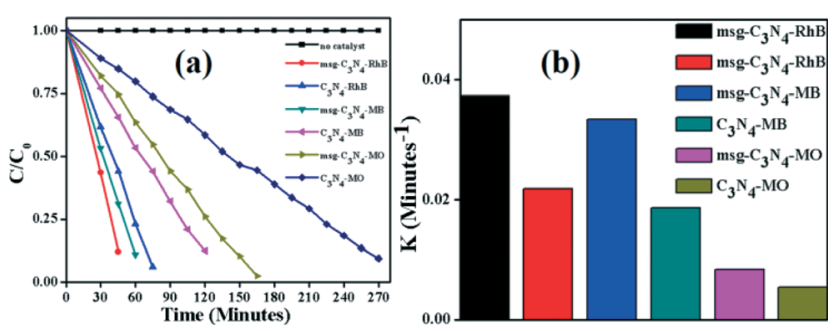

Fig. 5 (a) $C / C_{0}$ of $m s g-C_{3} N_{4}$ and $g-C_{3} N_{4}$ for RhB, $M B$ and $M O$. (b) First order rate constant $k\left(\mathrm{~min}^{-1}\right)$ of $\mathrm{msg}-\mathrm{C}_{3} \mathrm{~N}_{4}$ and $\mathrm{g}-\mathrm{C}_{3} \mathrm{~N}_{4}$ for $\mathrm{RhB}, \mathrm{MB}$ and $\mathrm{MO}$. 


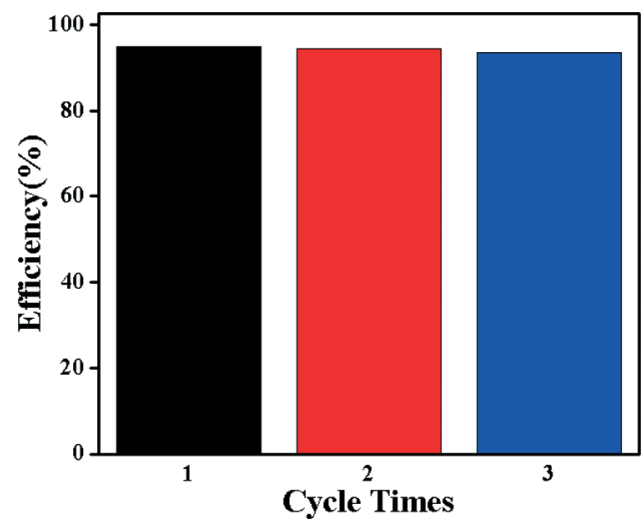

Fig. 6 Stability test of $m s g-C_{3} N_{4}$ over three consecutive cycles.

the stability test of $m s g-\mathrm{C}_{3} \mathrm{~N}_{4}$ was performed by reusing the same catalyst for a second time for the degradation of organic dyes under similar conditions. It was observed that upon reusing the material for several cycles, the performance of material remains same and there is no significance loss in efficiency, as shown in Fig. 6. The degradation efficiency of $\mathrm{msg}^{-} \mathrm{C}_{3} \mathrm{~N}_{4}$ decreased only $2 \%$ after three successive cycles, which indicates good stability and reusability of $\mathrm{msg}-\mathrm{C}_{3} \mathrm{~N}_{4}$ for several cycles without loss in activity at a pilot scale. The reactive nature of $m s g-C_{3} N_{4}$ towards the photocatalytic reaction comes from the availability of photogenerated electrons for superoxide radical generation. The tailored bandgap and light of an appropriate wavelength generate these electrons needed for the oxidation reaction. ${ }^{44}$

The photocatalytic activity of $\mathrm{msg}^{-} \mathrm{C}_{3} \mathrm{~N}_{4}$ is increased because of a positive shift in first order constant $k$ as a result of $\mathrm{H}_{2} \mathrm{O}_{2}$ addition (Table $\mathrm{S} 2 \dagger$ ). Therefore, $\mathrm{H}_{2} \mathrm{O}_{2}$ increases the rate of hydroxyl radical production e.g. $\mathrm{H}_{2} \mathrm{O}_{2}+\mathrm{e} \rightarrow \mathrm{OH}+\mathrm{OH}^{-}$ and enhances the efficiency of $\mathrm{msg}^{-} \mathrm{C}_{3} \mathrm{~N}_{4} \cdot{ }^{45}$ Also, a large surface area and higher aspect ratio provides more reactive sites for reaction, which further polishes the photodegradation efficiency of $\mathrm{msg}^{-} \mathrm{C}_{3} \mathrm{~N}_{4}$. It reduces the recombination probability of photoexcited charge carriers and enhances the transport of charges. $^{23-29}$

\section{Conclusions}

In summary, a facile, green and economical approach has been designed to synthesize novel msg- $\mathrm{C}_{3} \mathrm{~N}_{4} \cdot \mathrm{msg}_{-}-\mathrm{C}_{3} \mathrm{~N}_{4}$ exhibits higher potential for application as a visible light photocatalyst for degradation of organic pollutants. These studies indicate that novel $\mathrm{msg}^{-} \mathrm{C}_{3} \mathrm{~N}_{4}$ with high surface area and large aspect ratio can also be used for hydrogen production since it can provide more reactive sites. It reduces the recombination probability of photoexcited charge carriers and also increases the transport of charges. Strong PL intensity indicates that $m s g-\mathrm{C}_{3} \mathrm{~N}_{4}$ can be used as light-emitting materials. We anticipate that the $\mathrm{msg}-\mathrm{C}_{3} \mathrm{~N}_{4}$ will provide broad applications in the fields of photodetectors, field-effect transistors, optical waveguides, drug delivery, lithium-ion batteries, electro catalysts and light-emitting materials.

\section{Acknowledgements}

This work was supported by the National Natural Science Foundation of China $(21371023,50972017)$ and the Research Fund for the Doctoral Program of Higher Education of China (20101101110026).

\section{Notes and references}

1 M. R. Hoffmann, S. T. Martin, W. Choi and D. W. Bahnemann, Chem. Rev., 1995, 95, 69.

2 Y. Li, T. Sasaki, Y. Shimizu and N. Koshizaki, J. Am. Chem. Soc., 2008, 130, 14755.

3 X. Xiao and W. D. Zhang, J. Mater. Chem., 2010, 20, 5866.

4 D. M. Dalton and T. Rovis, Nat. Chem., 2010, 2, 710.

5 T. Yao, T. Cui, X. Fang, F. Cuia and J. Wu, Nanoscale, 2013, 5, 5896.

6 X. C. Wang, K. Maeda, A. Thomas, K. Takanabe, G. Xin, J. M. Carlsson, K. Domen and M. Antonietti, Nat. Mater., 2009, 8, 76.

7 S. C. Yan, Z. S. Li and Z. G. Zou, Langmuir, 2010, 26, 3894.

8 G. Liu, P. Niu, C. H. Sun, S. C. Smith, Z. G. Chen, G. Q. Lu and H. M. Cheng, J. Am. Chem. Soc., 2010, 132, 11642.

9 S. C. Yan, Z. S. Li and Z. G. Zou, Langmuir, 2009, 25, 10397.

10 L. Ge, C. C. Han, J. Liu and Y. F. Li, Appl. Catal., A, 2011, 410, 215.

11 Y. Wang, J. Yao, H.-R. Li, D. S. Su and M. Antonietti, J. Am. Chem. Soc., 2011, 133, 2362.

12 Y. Zheng, Y. Jiao, J. Chen, J. Liu, J. Liang, A. J. Du, W. M. Zhang, Z. H. Zhu, S. C. Smith, M. Jaroniec, G. Q. Lu and S. Z. Qiao, J. Am. Chem. Soc., 2011, 133, 20116.

13 K. Maeda, M. Higashi, D. Lu, R. Abe and K. Domen, J. Am. Chem. Soc., 2010, 132, 5858.

14 S. C. Yan, S. B. Lv, Z. S. Li and Z. G. Zou, Dalton Trans., 2010, 39, 1488.

15 L. Ge, C. C. Han and Liu, Appl. Catal., B, 2011, 108, 100.

16 Y. Wang, R. Shi, J. Lin and Y. Zhu, Energy Environ. Sci., 2011, 4, 2922.

17 Y. J. Zhang, T. Mori, L. Niu and J. H. Ye, Energy Environ. Sci., 2011, 4, 4517.

18 W. H. Shin, S. H. Yang, Y. J. Choi, H. M. Jung, C. O. Song and J. K. Kang, J. Mater. Chem., 2009, 19, 4505.

19 X. C. Wang, K. Maeda and X. F. Chen, J. Am. Chem. Soc., 2009, 131, 1680.

20 Y. J. Zhang, A. Thomas, M. Antonietti and X. C. Wang, J. Am. Chem. Soc., 2009, 131, 50.

21 X. J. Wang, H. Pang, S. Zhao, W. Shao, B. Yan, X. Li, S. Li, J. Chen and W. Du, ChemPhysChem, 2013, 14, 2518.

22 H. Pang, F. Gao and Q. Lu, CrystEngComm, 2010, 12, 406.

23 F. Idrees, C. Cao, F. K. Butt, M. Tahir, M. Tanveer, I. Aslam, Z. Ali, T. Mahmood and J. H. Hou, CrystEngComm, 2013, 15, 8146 . 
24 F. Dong, Z. Wanga, Y. Sun, W.-K. Ho and H. Zhang, Colloidal Material and Nanomaterials, 2013, vol. 401, 70.

25 L. Ge, C. Han, X. Xiao and L. Guo, Appl. Catal., B, 2013, $142,414$.

26 L. Zhu, W. D. Zhang, C. H. Chen, B. Xu and M. F. Hou, J. Nanosci. Nanotechnol., 2011, 11, 4948.

27 J. Xu, Y. Li, S. Peng, G. Lu and S. Li, Phys. Chem. Chem. Phys., 2013, 15, 7657.

28 Y. Cui, J. Zhang, G. Zhang, J. Huang, P. Liu, M. Antonietti and X. C. Wang, J. Mater. Chem., 2011, 21, 13032.

29 J. Hong, X. Xia, Y. Wang and R. Xu, J. Mater. Chem., 2012, $22,15006$.

30 S. C. Lee, H. O. Lintang and L. Yuliati, Chem.-Asian J., 2012, 7, 2139.

31 Q. Lv, C. Cao, C. Li, J. Zhang, H. Zhu, X. Kong and X. Duan, J. Mater. Chem., 2003, 13, 1241.

32 M. Tahir, C. Cao, F. K. Butt, F. Idrees, N. Mahmood, Z. Ali, I. Aslam, M. Tanveer, M. Rizwan and T. Mahmood, J. Mater. Chem. A, 2013, 1, 13949.

33 L. W. Yin, Y. Bando, M. S. Li, Y. X. Liu and Y. X. Qi, Adv. Mater., 2003, 15, 1840.

34 M. R. Wixom, J. Am. Ceram. Soc., 1990, 73, 1973.
35 X. Bai, C. Cao and X. Xu, Mater. Sci. Eng.: B, 2010, 175, 95.

36 H. Z. Zhao, X. L. Chen, C. C. Jia, T. Zhou, X. H. Qu, J. K. Jian and Y. P. Xu, Mater. Sci. Eng., B, 2005, 122, 90.

37 Q. Lv, C. B. Cao, C. Li, J. T. Zhang, H. S. Zhu, X. Kong and X. F. Duan, J. Mater. Chem., 2003, 13, 1241.

38 X. Bai, J. Li and C. Cao, Appl. Surf. Sci., 2010, 256, 2327.

39 J. Gao, Y. Zhou, Z. Li, S. Yan, N. Wang and Z. Zou, Nanoscale, 2012, 4, 3687.

40 Y. C. Zhao, Z. Liu, W. G. Chu, L. Song, Z. X. Zhang, D. L. Yu, Y. J. Tian, S. S. Xie and L. F. Sun, Adv. Mater., 2008, 20, 1777.

41 M. Hu, J. Reboul, S. Furukawa, L. Radhakrishnan, Y. Zhang, P. Srinivasu, H. Iwai, H. Wang, Y. Nemoto, N. Suzuki, S. Kitagawa and Y. Yamauchi, Chem. Commun., 2011, 47, 8124 .

42 K. Suenaga, M. Yudasaka, C. Colliex and S. Iijima, Chem. Phys. Lett., 2000, 316, 365.

43 P. Niu, G. Liu and H.-M. Cheng, J. Phys. Chem. C, 2012, 116, 11013.

44 M. Lee, C. Liao, C. Tsai and C. Chen, Adv. Mater., 2005, 17, 2493.

45 Y. S. Jun, E. Z. Lee, X. Wang, W. H. Hong, G. D. Stucky and A. Thomas, Adv. Funct. Mater., 2013, 23, 3661. 